\title{
Linear Quadratic Tracking Design for a Generic Transport Aircraft with Structural Load Constraints
}

\author{
John J. Burken ${ }^{1}$ \\ NASA Dryden Flight Research Center, Edwards, California, 93523 \\ Susan A. Frost ${ }^{2}$ \\ NASA Ames Research Center, Moffett Field, California, 94035
}

\begin{abstract}
When designing control laws for systems with constraints on the tracking performance, control allocation methods can be utilized. Control allocation methods are used when there are more command inputs than controlled variables. Control allocators can be used to address surface saturation limits, structural load limits, drag reduction constraints, or actuator failures. Most transport aircraft have many actuated surfaces compared to the three control variables (such as angle of attack, roll rate, and angle of sideslip). To distribute the control effort among the redundant set of actuators, a fixed mixer approach or online control allocation techniques can be utilized. The benefit of an online allocator is that complex constraints can be considered in the design; however, an online control allocator has the disadvantage of not guaranteeing a surface schedule, which can then produce unacceptable loads on the aircraft. The load uncertainty and complexity has prevented some controller designs from using advanced online allocation techniques. This paper considers actuator redundancy management for a class of over-actuated systems with real-time structural load limits using linear quadratic tracking applied to the generic transport model (a twin-engine heavy civil transport aircraft). With the inclusion of static load constraints in the allocator, the concern of overstressing the structures should be minimized or even eliminated. The results include three test cases. The first test case shows what happens when load constraints are applied over six left- and right-wing locations, with comparison to the same roll input run without load constraints. Test case two shows what happens when a large commanded roll is executed with the same load constraints as those used in test case one; this run is intended to stress the loads allocator. Test case three shows the robustness of the linear quadratic augmented allocator system to uncertainties; a 35-percent change in the control effectiveness plant model will be shown, in which the controller is kept the same as in test cases one and two with six load constraints.
\end{abstract}

\section{Introduction and Problem Statement}

$\Lambda$ goal of the National Aeronautics and Space Administration (NASA) Aeronautics Subsonic Fixed Wing Project is to reduce the environmental impact of civil aviation. The NASA, industry, universities, and other government organizations are researching advanced technologies and exploring novel civil transport configurations to achieve reductions in noise, emissions, and fuel burn for next-generation aircraft (NextGen). ${ }^{1}$ Some aircraft configurations are expected to have redundant and multi-purpose control effectors that cannot be easily incorporated into a conventional mixing algorithm that is determined a priori. ${ }^{2}$ Additionally, environmental goals may be addressed by using lightweight, flexible composite materials and aircraft configurations. The goal of lightweight structures is to reduce fuel consumption, which reduces the amount of engine pollutants.

An online control allocator does not necessarily guarantee a surface schedule; however, adding a particular control allocator does preserve the control schedule using linear quadratic design. It has been shown by Härkegård ${ }^{3}$ that for a particular class of nonlinear systems, using an $L_{2}$ control allocation method and linear quadratic control design give exactly the same design freedom in distributing the control effort among the actuators. Linear quadratic (LQ) controllers give very predictable surface commands for a given input, and the online control allocation method gives very predictable surface commands, in the "healthy case." The healthy case is when no constraints or failures

\footnotetext{
${ }^{1}$ Aerospace Engineer, Controls Branch, P.O. Box 273, MS 4840D AIAA Senior Member.

${ }^{2}$ Computer Engineer, Intelligent Systems Division, MS 269-3, AIAA Member.
} 
have occurred. When a constraint is hit, the online allocator method will not give the same surface commands as the LQ controller, and the predictability goes down, but the control system tracking is preserved better with the online allocator $^{3}$ compared to the LQ-only controller. This uncertainty, however, leads to unknown loads on the aircraft; for this reason advanced allocation methods have not been readily implemented on modern control systems.

Aircraft structural loads depend not only on the weight of the airplane for trimmed flight but also on the surface deflections used for maneuvering. The control surface movement is used in determining the total loads that the wing or aircraft encounters, along with static loads. This "surface schedule" is very predictable with a fixed mixer but not for online allocators. Therefore, the loads that the surface can produce with online allocators could violate the structural load limits while maneuvering. The task of this paper is to come up with a way to eliminate the load concerns for online allocators and to limit the loads while maintaining good tracking performance.

Pilot command systems for modern or conventional controllers track a state (alpha, $\alpha$, phi, $\varphi$, beta, $\beta$ ), or a state rate (p, q, or r), called control variables, by moving the control surfaces, or effectors. A vehicle is over-actuated if it has more independent control effectors than control variables. Figure 1 shows a typical control system block diagram without control allocation. The control allocation of over-actuated vehicles has been formulated as a constrained optimization problem by many researchers. ${ }^{4-10}$ A real-time online solution to the control allocation problem is advantageous in order to enable the system to run on future aircraft, such as NextGen. ${ }^{1}$ The term "NextGen" applies to civil transports that are "on the drawing board," prompting the search for numerical optimization methods that have good convergence properties and acceptable computational requirements. Several methods to solve the control allocation problem have been evaluated, including direct allocation, linear programming, quadratic programming, weighted pseudo-inverse, cascaded generalized inverse, and mixed optimization approaches. While optimal control allocation in flight control systems of fixed-wing aircraft is now feasible given the increased computational resources available on the aircraft, few studies have addressed the structural loads that are generated on the aircraft due to commanded control surface deflections. Figure 2a shows a control system block diagram with control allocation performed separately. As mentioned above, an online control allocator has the disadvantage of not guaranteeing a surface schedule, which can produce ill-defined loads on the aircraft. The load uncertainty and algorithm complexity has prevented some control designs from using advanced allocation techniques. For real-time optimal control allocation to be deployed on a civil aircraft there must be guarantees that the structural load limits of the aircraft will not be exceeded during flight. In Ref. 11, a new mixing law for a flexible transport aircraft was proposed to alleviate the wing bending moment during a sudden and strong roll maneuver with the additional goal of preserving nominal flight behavior. While the approach used an optimization algorithm to choose the control surface commands to be used for maneuver load alleviation, it was an off-line solution that was not used for real-time control allocation during normal flight. This paper presents an optimal allocator for a class of over-actuated systems with real-time onboard structural load feedback limits using linear quadratic tracking applied to the generic model of a transport-class aircraft. ${ }^{12}$ In this paper, a structural model is integrated with a simulation of a linear generic transport aircraft. The model is used to estimate the static structural loads on the aircraft during flight and to predict the loads generated by control surface deflections. The simulation is used to demonstrate and evaluate the proposed framework, which uses an optimal control allocator in the framework of a robust controller (linear quadratic regulator). The allocator ensures that the structural load limits of the aircraft are not exceeded. Figure $2 \mathrm{~b}$ shows a block diagram of the control law, the control allocation, and the structural loads model.

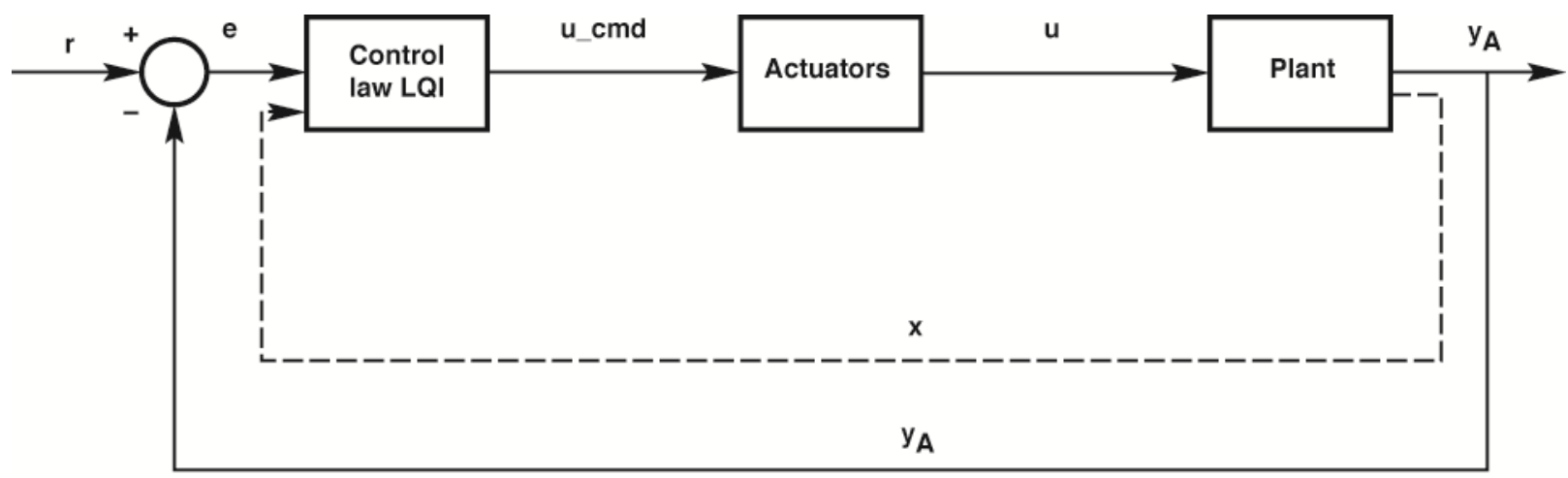

Figure 1. Block diagram of a typical control system. 


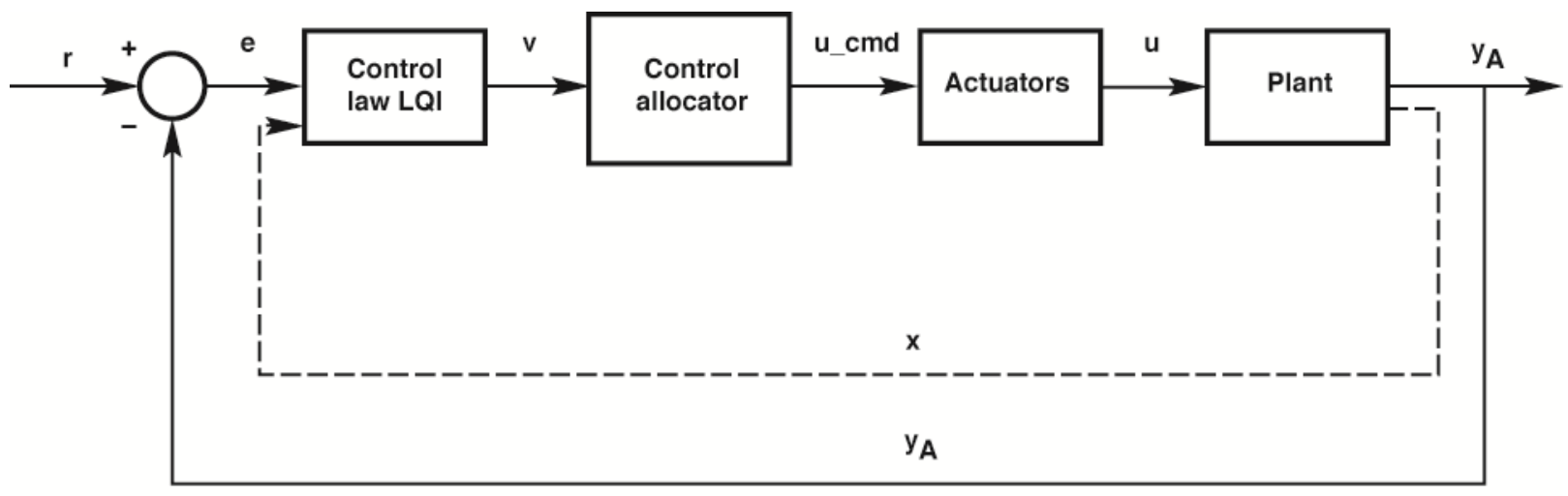

Figure 2a. Block diagram of a control system when a control allocation is performed separately.

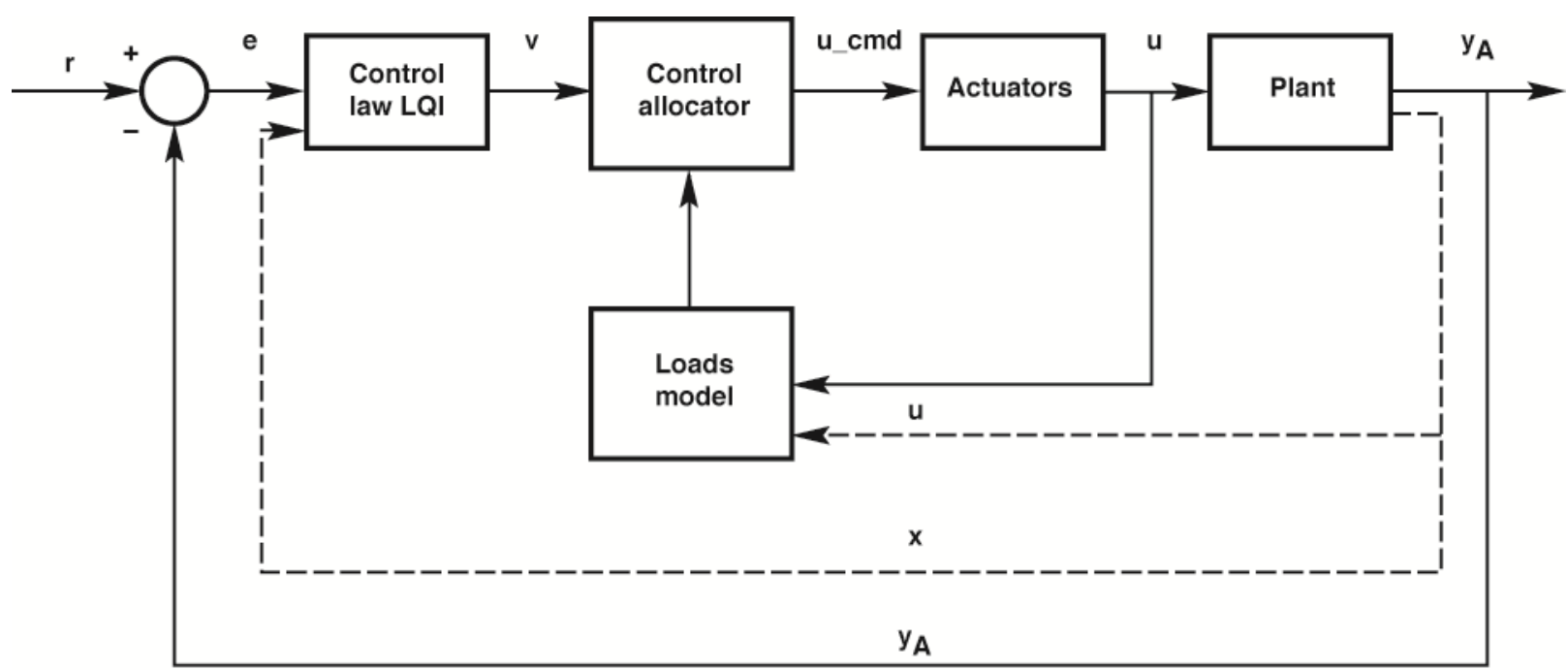

Figure 2b. Block diagram of a control system with control allocation and structural load constraints.

\section{Servomechanism Problem for Multi-Input/Multi-Output Systems}

The objective of this work is to seek robust control system designs that are easily implementable in flight software, are reliable, and that maintain structural integrity while providing reasonable command-tracking performance. To this end, a robust servomechanism approach is investigated and evaluated. The controller is a generalization of the classical proportional-plus-integral (PI) design and is sometimes referred to as linear quadratic tracker (LQT). The servomechanism problem is concerned with control of a dynamic system to achieve asymptotic tracking of desired output and rejection of un-measurable disturbance. For single-input/single output (SISO) systems the problem has been well understood for over 50 years; however, it is only in the last two decades that this problem has been solved for multi-input/multi-output (MIMO) systems. In the following sections, a MIMO LQT controller is introduced and the controller design methodology is reviewed with a type one input. For more details and a more complete discussion see Ref. 9.

\section{A. Problem Formulation}

Consider a linear, time-invariant, MIMO system, Eq. (1):

$$
\begin{aligned}
& x_{A}=A_{A} x_{A}+B_{u} u+E w \\
& y_{A}=C x_{A}+D u+F w \\
& \text { where } x_{A} \in R^{n}, u \in R^{p}, w \in R^{l}, y_{A} \in R^{q}
\end{aligned}
$$


For the LQT controller the reference, $r$, is equivalent to $y_{A}$ and the controller will track the output (see Figs. 1 or 2). The initial conditions for $w$ are assumed to be arbitrary; therefore, $w$ is considered unknown (un-measurable). In a more general formulation the dynamics of $r$ and $w$ do not have to be the same. ${ }^{9}$ They are assumed to be the same here for simplicity; such an assumption is adequate for the specific purpose of this paper. The objectives of the control design are to find a feedback controller such that 1) the closed-loop system is stable; 2) the error $\mathrm{e}=\mathrm{r}-\mathrm{y}_{\mathrm{A}}$ approaches zero in the presence of the un-measurable (possibly time-varying) disturbance, w; and 3) the closed-loop system is robust in the sense that asymptotic tracking of $r$ and rejection of $w$ are maintained in the presence of system parametric uncertainty or even variations in the order of the dynamics, as long as the closed-loop system remains stable.

\section{B. Robust Servomechanism Design Methodology}

A dynamic controller is to be designed to meet the stated objective. The controller dynamics are set to be, Eq. (2):

$$
\begin{aligned}
& x_{c}=A_{c} x_{c}+B_{c}\left(r-Y_{A}\right) \\
& \text { where } x_{c} \in R^{q} \text { and } A_{c} \in R^{q \times q} \text { and } B_{c} \in R^{q \times q}
\end{aligned}
$$

The controller states are $x_{c}$. Now consider the open-loop system including the plant in Eq. (1) and the controller dynamics in Eq. (2) with $\mathrm{r}=0$, Eq. (3):

$$
\left[\begin{array}{c}
\dot{x_{A}} \\
\dot{x_{c}}
\end{array}\right]=\left[\begin{array}{cc}
A_{A} & o \\
-B_{c} C & A_{c}
\end{array}\right]\left[\begin{array}{l}
x_{A} \\
x_{c}
\end{array}\right]+\left[\begin{array}{c}
B_{u} \\
-B_{c} D
\end{array}\right] \mathrm{u}
$$

Suppose that the following condition, Eq. (4), is satisfied:

$$
\operatorname{rank}\left[\begin{array}{cc}
\lambda I-A_{A} & B_{u} \\
-C & D
\end{array}\right]\left[\begin{array}{l}
x_{A} \\
x_{c}
\end{array}\right]=n+q
$$

Then the augmented system, Eq. (3) is controllable. ${ }^{9}$ Equation (4) states that the rank of the closed-loop system must equal the sum of the initial number of states of $\mathrm{A}_{\mathrm{A}}$ plus the number of tracking states, $\mathrm{x}_{\mathrm{c}}$. Solving the continuoustime algebraic Riccati equation for $\mathrm{K}=\mathrm{f}\left(\mathrm{K}_{\mathrm{A}}, \mathrm{K}_{\mathrm{c}}\right)$, there exists a virtual control law, Eq. (5):

$$
v=K_{A} x_{A}+K_{c} x_{c}=K\left[x_{A} ; x_{c}\right]
$$

such that the closed-loop system is stable. Furthermore, when $r \neq 0$, asymptotic tracking and disturbance rejection are achieved by such a control law. That is, $e=r-y \rightarrow 0$ for any initial condition $x(0)$. The closed-loop system possesses robustness in the sense that for any (not necessarily small) perturbations in $\left\{A_{A}, B_{u}, C, D, B_{c}, K_{A}, K_{c}\right\}$, asymptotic tracking and disturbance rejection still hold as long as the closed-loop system remains stable. ${ }^{9}$ The number of integrators for the MIMO system is equal to the number of outputs $y_{A}$.

The control allocation problem comes down to determining a feasible control input, u, such that Eq. (6):

$$
B u=v
$$

The problem is to determine $(u)$ such that $B u$ approximates $v$ as well as possible (Ref. 13). An explicit solution to Eq. (6) without control allocation constraints is the pseudo-inverse, or the Moore-Penrose inverse of $B$ :

$$
B^{\dagger}=B^{T}\left(B B^{T}\right)^{-1}
$$


The output of Eq. (5) is a virtual command to each axis, which becomes the desired acceleration for the control allocator.

\section{Linear Quadratic with Control Allocation}

The problems are whether the control allocator can give exactly the same control effort as the well understood linear quadratic (LQ) method without failures or constraints, and how to command all of the surfaces from a virtual command output. These very problems were addressed by Ola Härkegård ${ }^{3,14}$ using an $\mathrm{L}_{2}$ optimal control allocator. For a discussion of the allocator presenting the same control effort issue, see Härkegård. ${ }^{3}$ For the underdetermined control allocation problem you must solve the system for the state in which the virtual commands are distributed among many surfaces (the state in which the number of control surfaces outnumbers the virtual commands). Thus, Eq. (6) is set to Eq. (7):

$$
B_{u}=v=v_{d}
$$

Section III, "Optimization Formulations of Control Allocation," develops the design of the allocator. Section IV, "Control Allocation with Structural Load Constraints and Load Feedback," includes the structural loads in the allocator. The output of Eq. (5) is the virtual command to each axis, which becomes the desired acceleration for the control allocator.

\section{Remarks:}

(1) Because the augmented system, Eq. (3), is controllable, the control law, Eq. (5), can be conveniently found by applying the linear quadratic regulator approach to Eq. (3).

(2) From the controller dynamics, Eq. (2), it can be seen that $x_{c}=\int(r-y) d t=\int(e) d t$. Thus, the control law, Eq. (5), is simply a PI control law, which is well known in classical SISO control theory. The current formulation is much more general in that it applies to MIMO systems and allows tracking of time-varying commands and rejection of time-varying disturbances. ${ }^{9}$

(3) The output for the control is a virtual system in the sense of there being three axes to control. Thus, the dimension of the virtual signal (see Fig. $2 b$ ) is equal to the number of controlled states.

The baseline controller discussed in this paper will be the robust servomechanism without any structural load limitations. The virtual control input $(v)$ has three axes to track (pitch, roll, and yaw) and distribute (allocate) the commands among the 12 surfaces. The upcoming section will treat the problem of solving the virtual input and output of the allocator, where the output of the allocator is the true control input (see Fig. 2a or $2 \mathrm{~b}$ ) to the actuators. The control allocator solves an underdetermined system of equations where $v \in R^{\mathrm{q}}$ and $u \in R^{p}$ and where $p>q$.

\section{Optimization Formulations of Control Allocation}

The following section covers the details needed to go from the virtual command to the actual surface commands. The surface commands will have the added burden of staying within the structural load limits.

\section{A. Control Allocation Design}

We introduce control allocation in the context of linear quadratic tracking command. This linear quadratic control outputs a virtual command for each axis that is to be controlled; thus, the dimension of the LQT controller is $v \in R^{3 \times l}$. Obtaining $u$ from $v_{d}$ requires solving a system of linear equations having more unknowns than equations. Solving such a system is not difficult in itself; the difficulty in control allocation is that the vector, $u$, is constrained. The limits generally have the form shown in Eq. (8):

$$
u_{\min , i} \leq u_{i} \leq u_{\max , i} \text { for } i=1, \ldots, p
$$

where $p$ is the number of surfaces. In vector form, Eq. (8) is written as $u_{\min , i} \leq u_{i} \leq u_{\max , i}$. There may be additional constraints due to the maximum rate of deflection of the actuators. We refer to the problem of finding a vector, $u$, that is the "best" possible solution of Eq. (6) within the constraints of Eq. 8 as the control allocation problem. Rewriting the terms from Eq. (6) and Eq. (8) together, the standard constrained linear control allocation problem is: 


$$
\begin{gathered}
B u=v \\
\underline{u} \leq u \leq \bar{u}
\end{gathered}
$$

Given the constraints, the control allocation problem may be such that many exact solutions exist, only one exact solution exists, or no exact solution exists.

One is naturally drawn to finding either exact solutions or approximate solutions that minimize the error $B u-v d$. Indeed, providing all the control authority available may determine whether a maneuver is achievable, and whether an unusual condition can be recovered from or not. The question also arises, however, as to which solution is the most desirable when many solutions exist; therefore, optimal control allocation typically consists both of error minimization and control optimization. As we will discuss in this paper, the objective of load minimization, or at least load limiting, may also become part of the control allocation problem.

\section{B. Formulations of Optimal Control Allocation}

The norm used in the allocation criteria is a design choice that has more consequences than might be expected. The $l_{1}$ norm of a vector, $x$, is the sum of the absolute values of the elements of the vector, Eq. (9):

$$
\|x\|_{1}=\sum_{i=1}^{n}\left|x_{i}\right|
$$

while the $l_{2}$ norm is the usual Euclidean norm, Eq. (10):

$$
\|x\|_{2}=\sqrt{\sum_{i=1}^{n}\left|x_{i}\right|^{2}}
$$

and the $l_{\infty}$ norm is the sup norm, Eq. (11):

$$
\|x\|_{\infty}=\sup \left|x_{i}\right|
$$

Algorithms have been proposed for all three norms; and results of the optimization problems are sometimes quite different. $^{15,16}$

A possible implementation of optimization for control allocation consists in the sequential minimization of the error vector and of the control vector. Specifically, the error is minimized first, and then the control vector is minimized among all equivalent solutions. In Ref. 8, the control minimization problem was solved only when the solution of the primary error minimization problem was $J=0$. It should be noted, however, that unless the matrix, $B$, satisfies specific conditions (any $q \times q$ submatrix of $B$ must be nonsingular), the solution is not necessarily unique, even if the desired vector $v_{d}$ is not feasible. Given this fact, mixed optimization is a good choice, and has several advantages over sequential optimization.

Mixed optimization: Given a matrix, $B$, and a vector, $u_{p}$, find a vector, $u$, such that Eq. (12):

$$
J=\left\|B u-v_{d}\right\|+\varepsilon\left\|u-u_{p}\right\|
$$

is minimized, subject to $u_{\min } \leq u \leq \max$.

The mixed optimization problem combines the error and control minimization problems into a single problem through the use of a small parameter, $\varepsilon$. If the parameter $\varepsilon$ is small, priority is given to error minimization over control minimization, as is normally desired. Often, the combined problem may be solved faster, and with better numerical properties, than when the error and control minimization problems are solved sequentially. ${ }^{5}$

\section{Implementation of Optimal Control Allocation Algorithms}

Computational resources available on modern aircraft make the use of optimal control allocation algorithms feasible in real time. An efficient algorithm to solve the mixed optimization problem given in Eq. (12) with the $l_{1}$ 
norm on the criterion was formulated by Bodson using linear programming approaches, providing guaranteed convergence to a solution in an acceptable period of time. ${ }^{5}$ Timing data showed that solutions of the problem could comfortably be performed in real time, even for large numbers of actuators.

Härkegård proposed an elegant solution of the optimal control allocation problem using the $l_{2}$ norm and the theory of active sets. ${ }^{14}$ The algorithm was very similar to the simplex algorithm used for $l_{1}$ optimization, and had the same advantage of completing in finite time and with a small number of iterations. The $l_{2}$ norm is noted for distributing the control effort among the control surfaces more evenly than the $l_{1}$ norm, which uses the most effective surfaces. ${ }^{16}$ To more evenly distribute the control effort among the control surfaces when using a linear programming approach, in Ref. 17, the $l_{\infty}$ norm was introduced for control minimization with the $l_{1}$ norm still being used for the error minimization.

\section{Control Allocation with Structural Load Constraints and Load Feedback}

Most optimal control allocation algorithms find an optimal solution to the control allocation problem within the constraints of the control surface position and possibly rate limits. These constraints, however, are not sufficient to ensure that the structural load limits of the aircraft will not be exceeded by the commanded control surface deflections. The bending and torsion moments at the wing root are examples of loads on the aircraft that need to be monitored. Structural load constraints will need to be accounted for in order to deploy optimal control allocation on NextGen ${ }^{1}$ aircraft. The load constraints at discrete critical points on the aircraft are formulated as shown in Eq. (13):

$$
\|M+T \Delta u\| \leq L_{\max }
$$

where $M$ is a vector of the current measured or estimated loads at the critical points, $T$ is a matrix that converts the effect of incremental surface deflections into incremental structural loads, and $L_{\max }$ is a vector of maximum allowable structural loads at the critical points. The loads that need to be limited are a function of the aircraft being considered, often with an emphasis on torsion and bending moments. Generally, the load limits are determined through detailed studies, including ground- and flight-testing. This paper does not address the selection of the location or the number of load points to be considered for a given problem. For the purpose of developing a representative example, load points along the aircraft wing are used.

Assume that the $T$ matrix, which is computed from the states of the aircraft at the current time, gives a linear approximation of the incremental structural loads arising from commanded surface deflections. The incremental loads matrix is formed from an on-board loads model by perturbing each control surface input to the model from its current position at the current aircraft state. The perturbation yields the change in aerodynamic lift and rolling moments due to a one-degree change in surface deflection. It is assumed that the entire aircraft lift is distributed elliptically across the wing; also assumed is that the control effectiveness of each surface is proportional to the lift generated by that control surface. The resulting lift and moment components are used in conjunction with a structural model of the aircraft to determine moments at critical points on the aircraft. Superposition of the control surface effects in terms of lift, moments, and structural loads is assumed in order to obtain a reasonable, but tractable solution in real time.

\section{Proof-of-Concept Simulation Architecture}

Here we describe the proof-of-concept simulation implemented to demonstrate the proposed framework assuming static loads, an elliptical lift distribution, and a limited number of critical load points, using bending moments only. The structural load model used in this paper is identical to the model used in Ref. 18.

\section{A. Aircraft Configuration and Aerodynamic Model}

A linear simulation of a generic-class-type transport aircraft is used for the proof-of-concept study of the proposed framework. The Generic Transport Model is used to investigate dynamics modeling and control of large transport vehicles in upset conditions. ${ }^{12}$

The simulation created for this study represents a conventional modern midsize commercial passenger configuration. The aircraft has right and left inboard and outboard elevons, three ailerons on each wing, and upper and lower rudders for use by the control allocator to achieve the desired roll, pitch, and yaw moments commanded by the flight control system. A stabilizer is used for trimming the aircraft.

For the proof-of-concept study, six critical points on the aircraft were monitored for bending moments. These critical points were located on each wing near the six ailerons (three on the left wing and three on the right wing). 
Figure 3 shows the right wing with three ailerons and three load limit locations. The left wing is similar. The loads locations that will be limited in this paper will be the six nodes (1 to 6) or (Ail_LOB, Ail_LMB, Ail_LIB, Ail_RIB, Ail_RMB and Ail_ROB ). Comparisons are made between the allocator having no load limits and having load limits using the LQT controller. Further analysis and reporting will be performed to define more realistic load limits which will include torsion load components, in addition to the static bending moments shown in this paper.

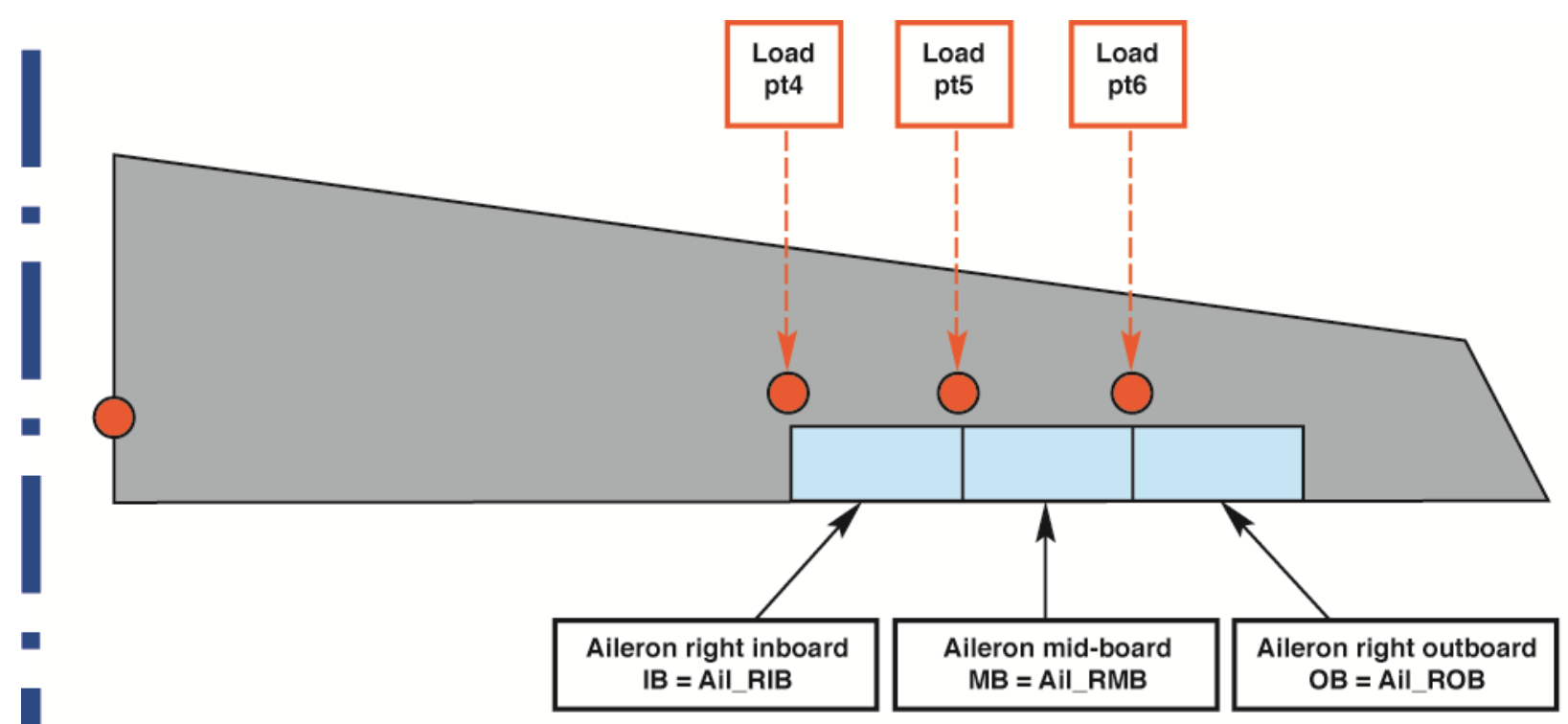

Figure 3. Right-wing layout with three ailerons and three constrained load points (Ail_RIB, Ail_RMB and Ail_ROB). The left wing is similar, with load points Ail_LOB, Ail_LMB and Ail_LIB, for a total of six load points.

\section{B. Static Structural Model and Wing Layout}

A finite element analysis (FEA) model is developed and integrated into the simulation to estimate static structural loads on the aircraft due to lift and roll moments and to compute the incremental loads created by surface deflections. ${ }^{18}$ For the proof-of-concept study, only bending moments at the wing root and aileron locations are monitored and included in this paper. It is important to note that torsion moments will contribute loads to the aircraft; torsion will be included in future studies. The finite element method is employed for its ability to calculate wingspan internal loads for potentially complex wingspan load distributions and wing geometries. The basic FEA model requires a small number of matrix multiplications for static loads analysis. The structural modeling and analysis used for this study assumes static conditions and considers external loads on the wing due to aerodynamic lift forces and roll moments. The lift distribution on each wing is assumed to be elliptical, with each wing carrying half of the total aircraft lift.

\section{Stability and Control Augmentation System with Optimal Control Allocation}

The stability and augmentation system for the simulation uses an LQT controller. The simulation has multiple surfaces that control multiple axes. The control allocator is able to use these surfaces to achieve the desired roll, pitch, and yaw moments commanded by the flight control system. The allocator has inputs for measured load, $M$, the incremental load matrix, $T$, for predicting the control surface contribution to the load at the critical points, a preferred position up, surface position limits, and load limits. The load limits are incorporated as a constraint on the cost function. Since this paper is examining the feasibility of the framework, we are only considering the load constraint on the bending moment at the six critical points along the wings. The control allocation problem solved in this simulation is to find the vector, $u$, such that Eq. (14):

$$
J=\left\|B u-v_{d}\right\|_{1}+\varepsilon\left\|u-u_{p}\right\|_{1}
$$

is minimized, subject to $u_{\min } \leq u \leq u_{\max }$ and $\|M+T \Delta u\| \leq L_{\max }$. The above criterion and constraints are converted to a linear program and solved using the revised simplex algorithm described in Section III.C, "Implementation of 
Optimal Control Allocation Algorithms," which was modified to include the load constraints. The control allocator does not have actuator rate limits as a constraint, but the actuators modeled in the simulation rate limit their commands. The control allocator weighted the control minimization criterion by setting $\varepsilon=10^{-2}$. Scaling of some of the inputs to the control allocator was necessary to achieve good numerical properties for the algorithm. The parameters $B$ and $v_{d}$ were scaled by a factor of $10^{-3}$ and the structural load parameters $M, T$, and $L_{\max }$ were scaled by a factor of $10^{-2}$.

\section{Simulation Results}

The results include three test cases. The first test case shows what happens when load constraints are applied over six left- and right-wing locations, compared to the same input run without load constraints for roll input. Test case two shows what happens when a larger commanded roll is executed with the same load constraints as test case one. This run is intended to stress the loads allocator. In test case three, to show the robustness of the linear quadratic augmented allocator system to uncertainties, a 35-percent change in the control effectiveness plant model will be shown, keeping the controller the same as in test cases one and two with load constraints. We chose a roll doublet for the proof-of-concept criterion because the aileron deflections will load or unload the wing forces and moments. The simulations were run after the aircraft was trimmed at Mach 0.70 and an altitude of 30,000 $\mathrm{ft}$ at a weight of $200,100 \mathrm{lb}$.

Test case one: Small roll maneuver with the load constraints applied over six left- and right-wing locations (nodes near the Ail_LOB, Ail_LMB, Ail_LIB, Ail_RIB, Ail_RMB and Ail_ROB).

Figures 4, 5, and 6 show the time history plots for test case one. The first run (blue lines) was without load limits and the second run (red lines) was with six aileron load limits. The six load nodes are Ail_LOB, Ail_LMB, Ail_LIB, Ail_RIB, Ail_RMB and Ail_ROB and were arbitrarily set at 7250, 10000, 12950, 12950, 10000, and $7250 \mathrm{ft}-\mathrm{lb}$, respectively). The control allocator needs to keep the loads below the specified levels. Figure 4 shows the aircraft response for both runs plotted together. The roll performance is the same but the alpha trace is slightly different. The loads on the left- and right-wing critical points are shown in Fig. 5; these load points are very close to the ailerons. No load limits were broken during the maneuver with active load limiting. The aileron deflections for the commanded maneuver are shown in Fig. 6. A feature of optimal control allocation algorithms with $1_{1}$ norms on the control error is that the solutions will be such that the most effective surfaces are used to achieve the command; to achieve the roll command effectively, the ailerons that are most effective are utilized, those being the outboard ailerons Ail_LOB, Ail_ROB (see blue lines). The left aileron was practically stopped by the allocator because the load limit was touched (Ail_LOB load limit $7250 \mathrm{ft}-\mathrm{lb}$ ). See the red lines in Figs. 5 and 6. The results show the performance is not exactly the same between the two runs, but is very close to being the same. 

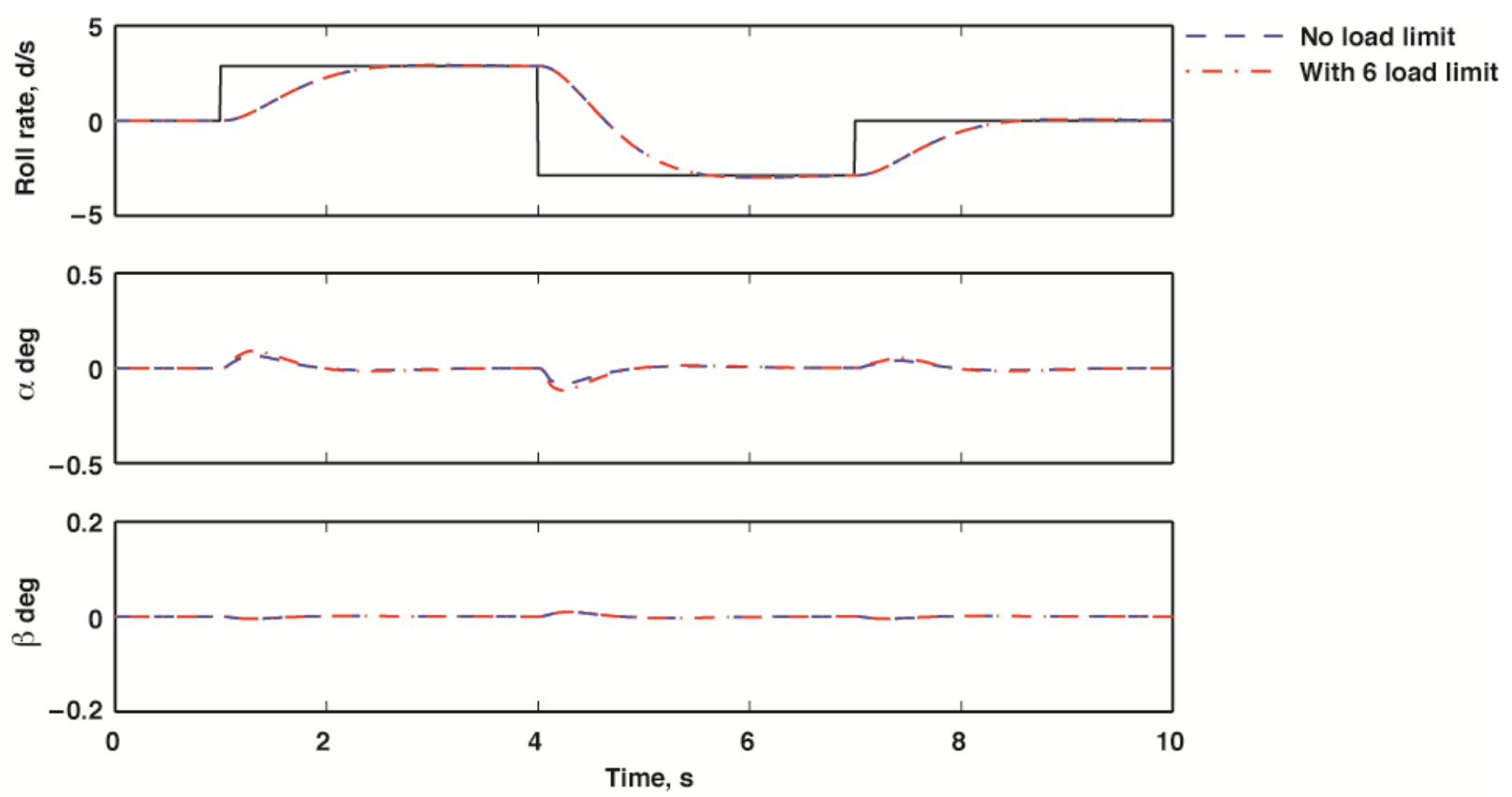

Figure 4. Time history of commanded roll rate and state responses with (red lines) and without load limits (blue lines) for test case one.
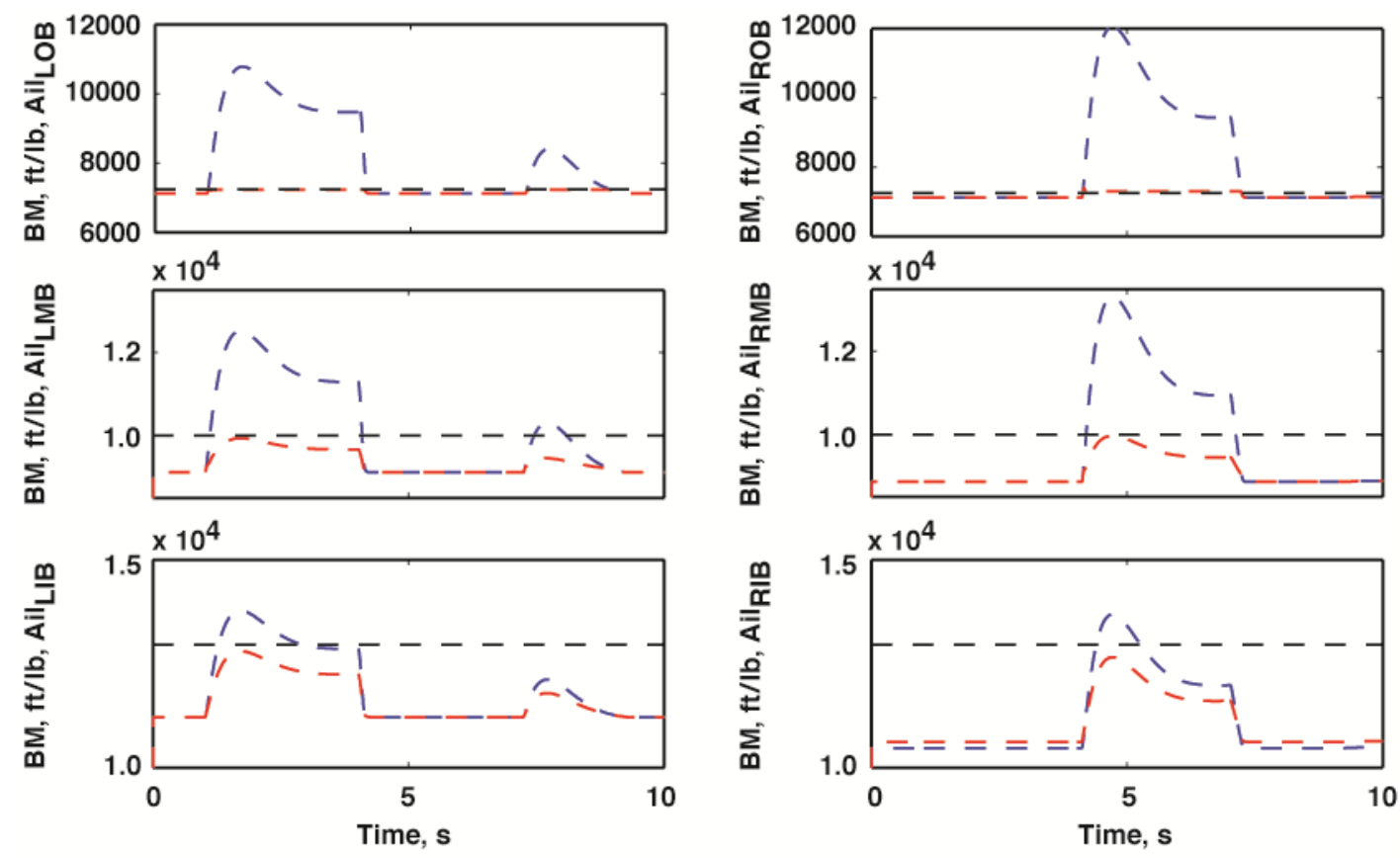

Figure 5. Bending moments (ft-lb) at six left- and right-wing critical points with and without load limit of (7250, 10000, and $12950 \mathrm{ft}-\mathrm{lb})$ for test case one. Red lines are with load limits, blue lines are without; black lines represent the limit at each point. 

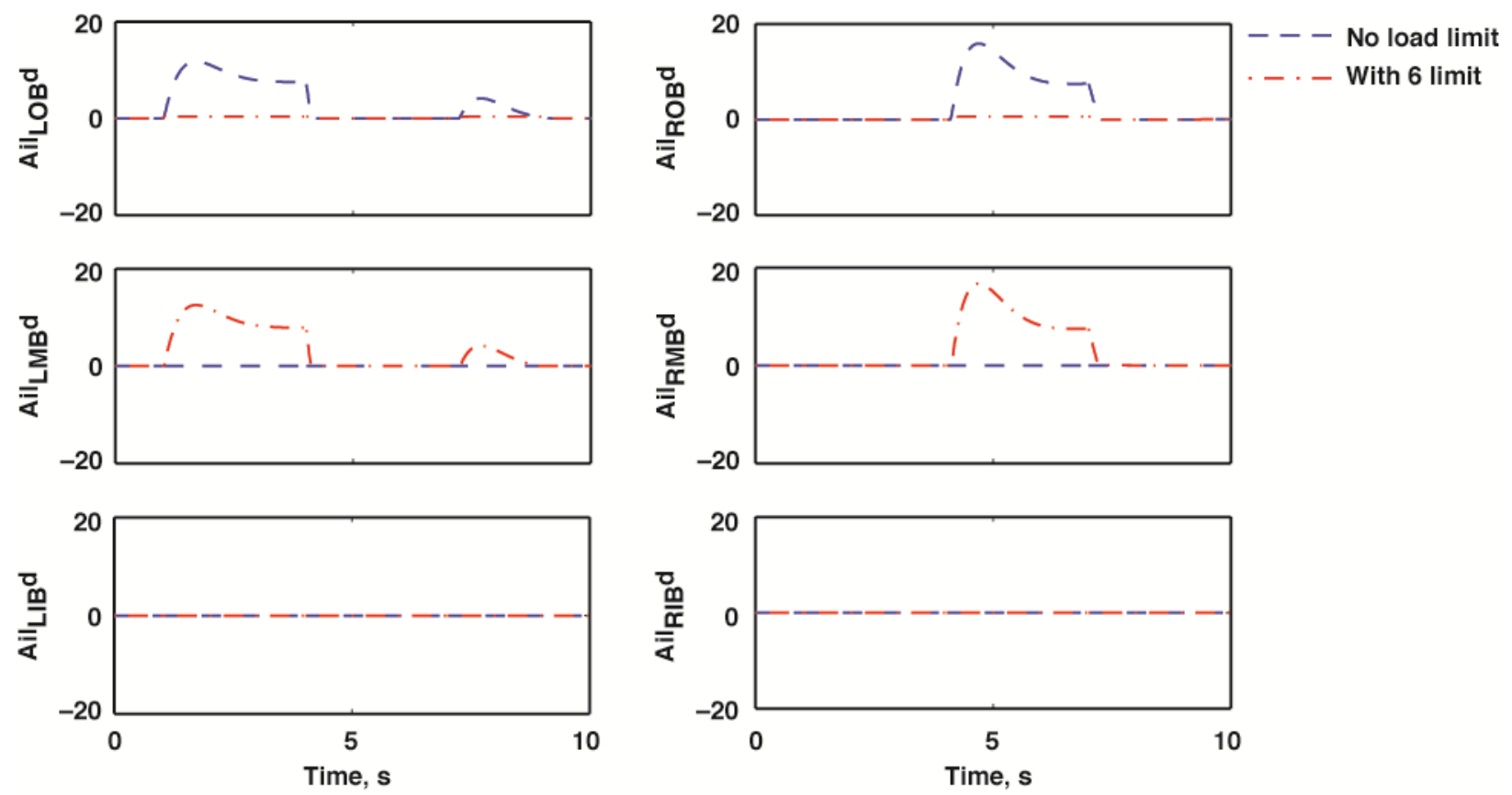

Figure 6. Aileron deflections (deg) on left and right wings with (red dash-dot line) and without (blue dashed line) load limits for test case one in which there were six load constraints.

Test case two: Large roll maneuver with the load constraints applied over six left- and right-wing locations near (nodes Ail_LOB, Ail_LMB, Ail_LIB, Ail_RIB, Ail_RMB and Ail_ROB).

The same flight conditions and type of maneuvers were performed for test case two as for test case one, however, the roll maneuver was larger in order to test the allocator with a harder stress case. Figure 7 shows the aircraft response for both runs plotted together. The loads on the ailerons are shown in Fig. 8. The aileron deflections for the commanded maneuver are shown in Fig. 9. The roll performance with load limiting is worse than without load limiting; however, the allocator maintained the loads below the critical levels at the cost of good roll tracking performance. No load limits were broken during the maneuver. 

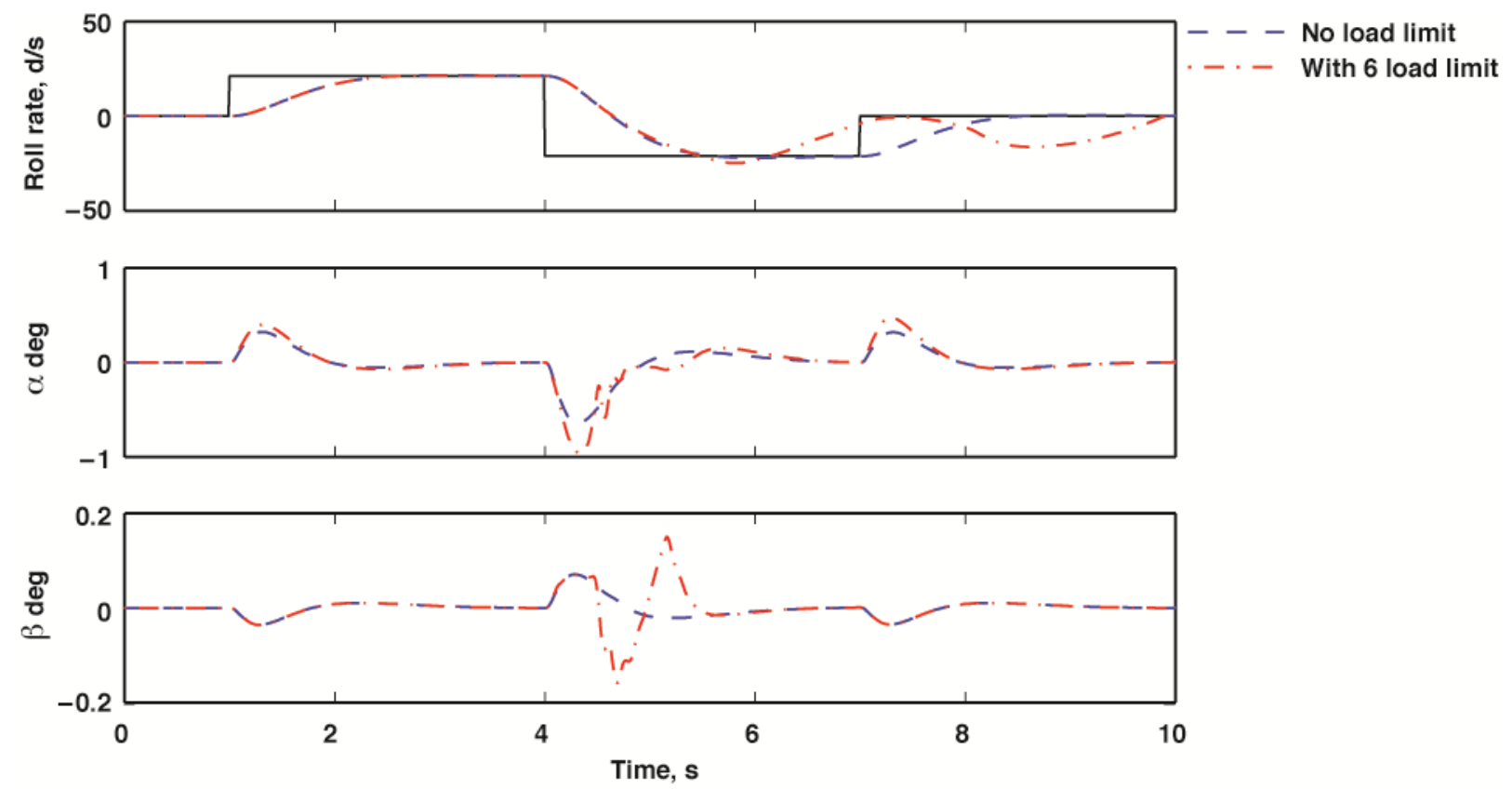

Figure 7. Time history of commanded roll rate and state responses with six load limits (red lines) and without load limits (blue lines) for test case two, which has a large roll command.
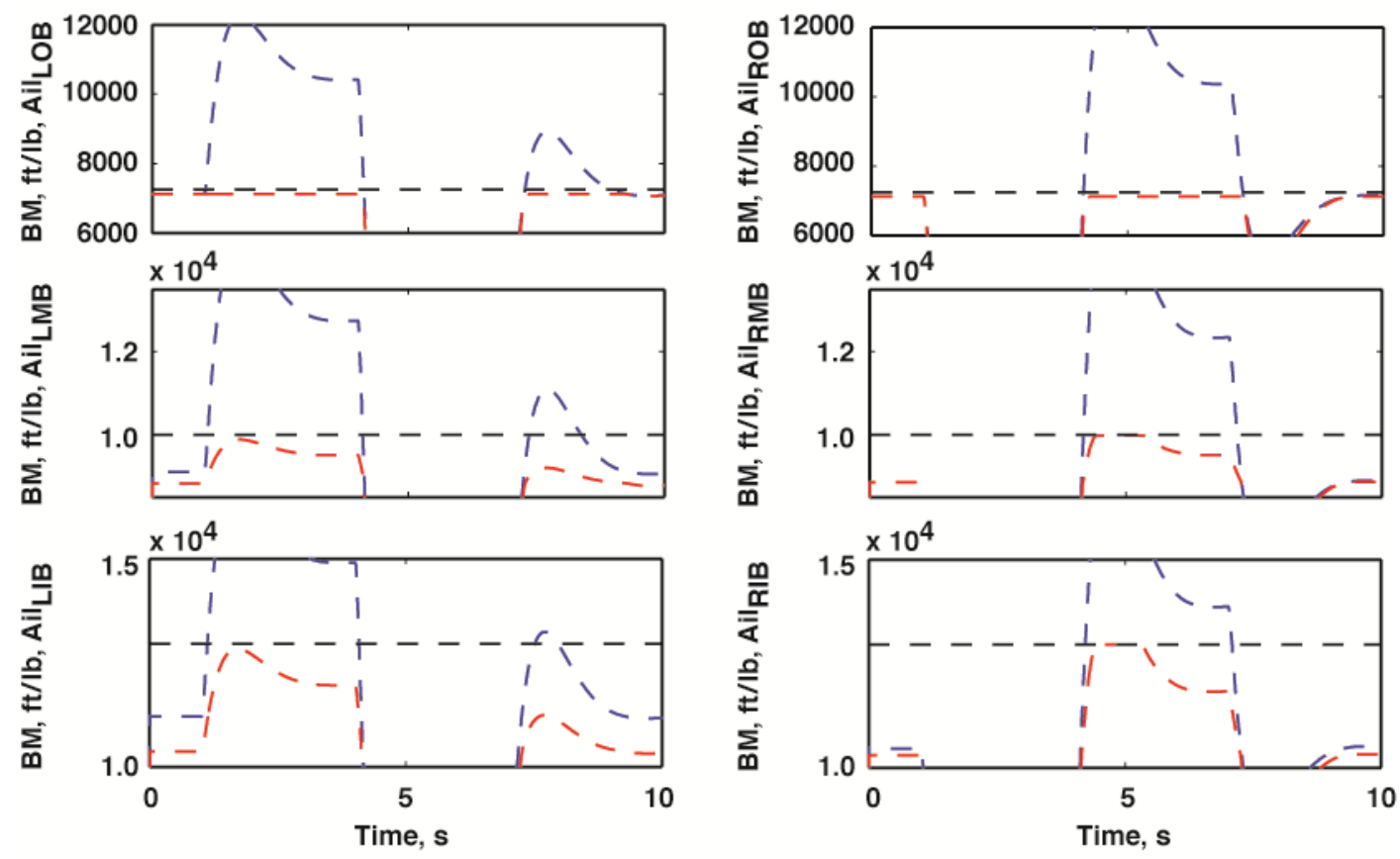

Figure 8. Bending moments (ft-lb) at six left- and right-wing critical points with and without load limit of (7250, 10000, and $12950 \mathrm{ft}-\mathrm{lb})$ for test case two, which has a large roll command. Red lines are with load limits, blue lines are without; black lines represent the limit at each point. 

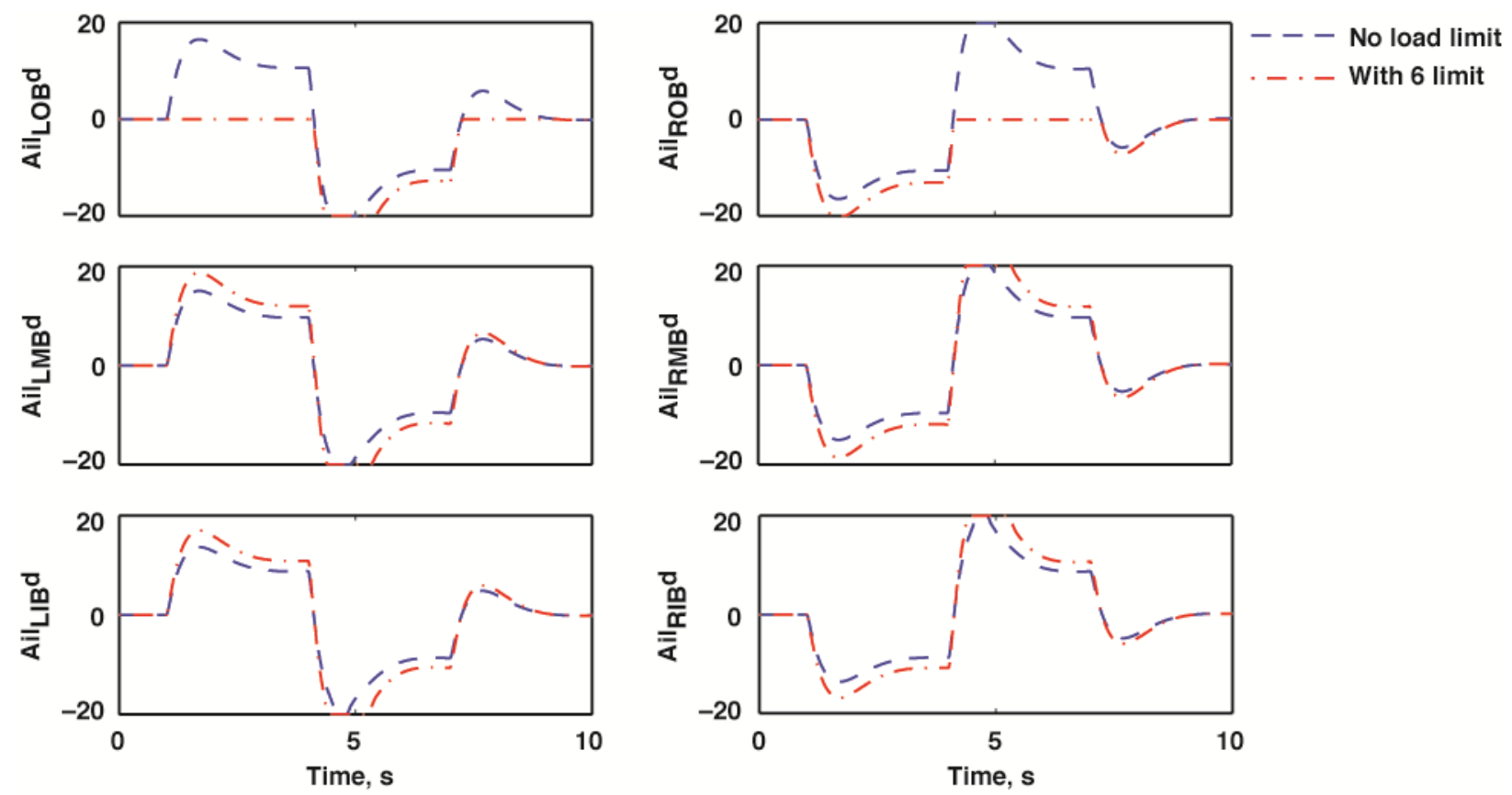

Figure 9. Aileron deflections (deg) on left and right wings with and without load limits for test case two in which there were six load constraints. Blue line is without load limits; red lines are with six limits. The aileron surface limits were +/- $20 \mathrm{deg}$.

Test case three: Simple roll maneuver with a 35-percent change to the plant model with six load limits.

The final test case compared the robustness of the LQT controller and allocator to large plant uncertainties with the same six load limit constraints that were used in test cases one and two. The plant model control effectiveness, $B_{u}$ was changed by 35 percent for the second run (red lines) with the load limits active. The first run had no uncertainties or load limits. Figure 10 shows the aircraft response for both runs plotted together. The results show the performance is slightly slower with the uncertainty and load limit run (red lines) compared to the nominal run (blue lines). The loads on the left- and right-wing critical points are shown in Fig. 11. No load limits were broken during the maneuver. The aileron deflections for the commanded maneuver are shown in Fig. 12. The outboard ailerons were prevented from moving due to the load constraints imposed by the allocator (see Figs. 11 and 12), but the mid-board ailerons engaged to achieve good roll tracking performance. 

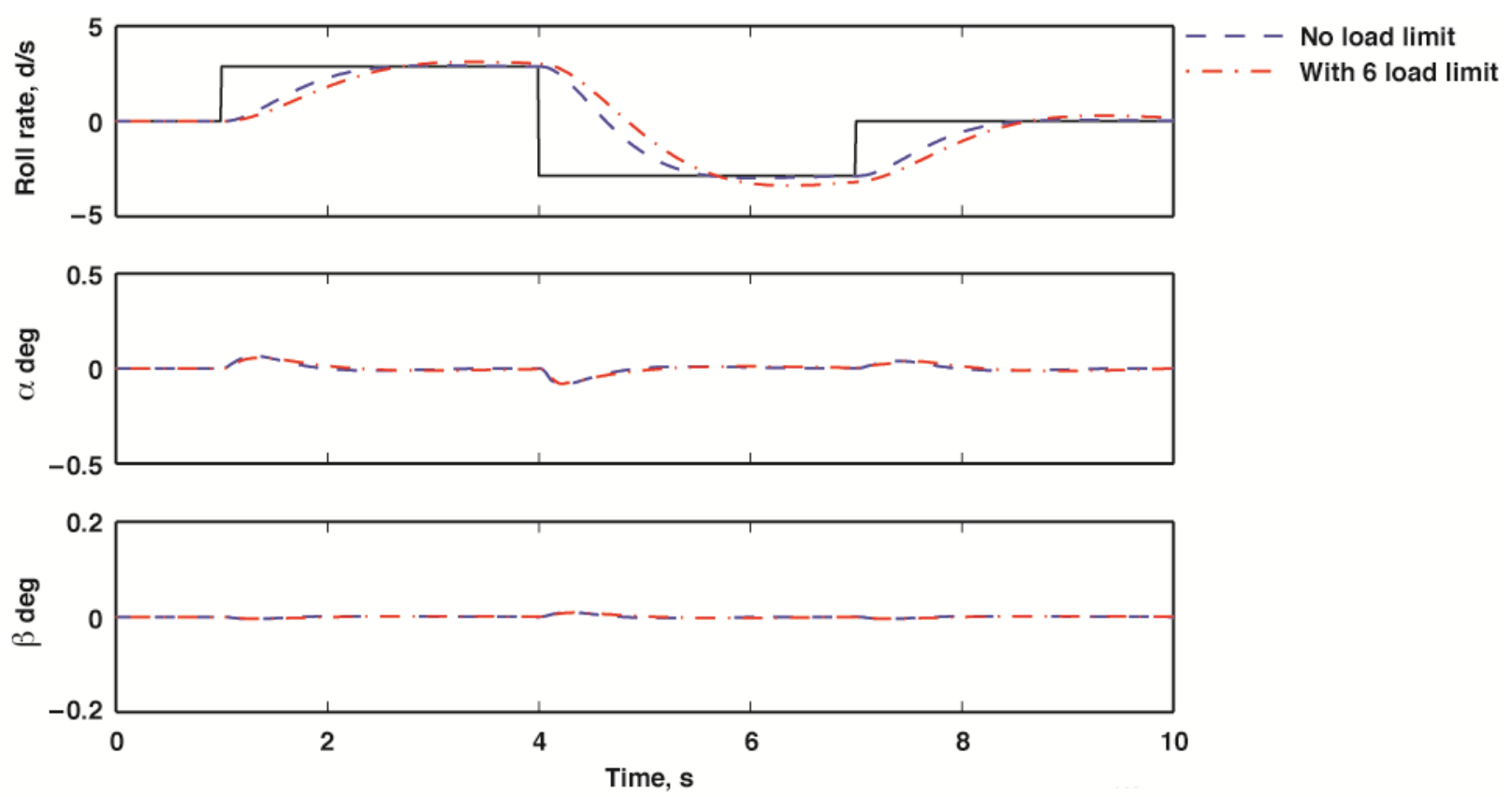

Figure 10. Time history of commanded roll rate and state responses with 35-percent uncertainty (red lines) and without (blue lines) for test case three, which has a 35 -percent control effectiveness reduction change.
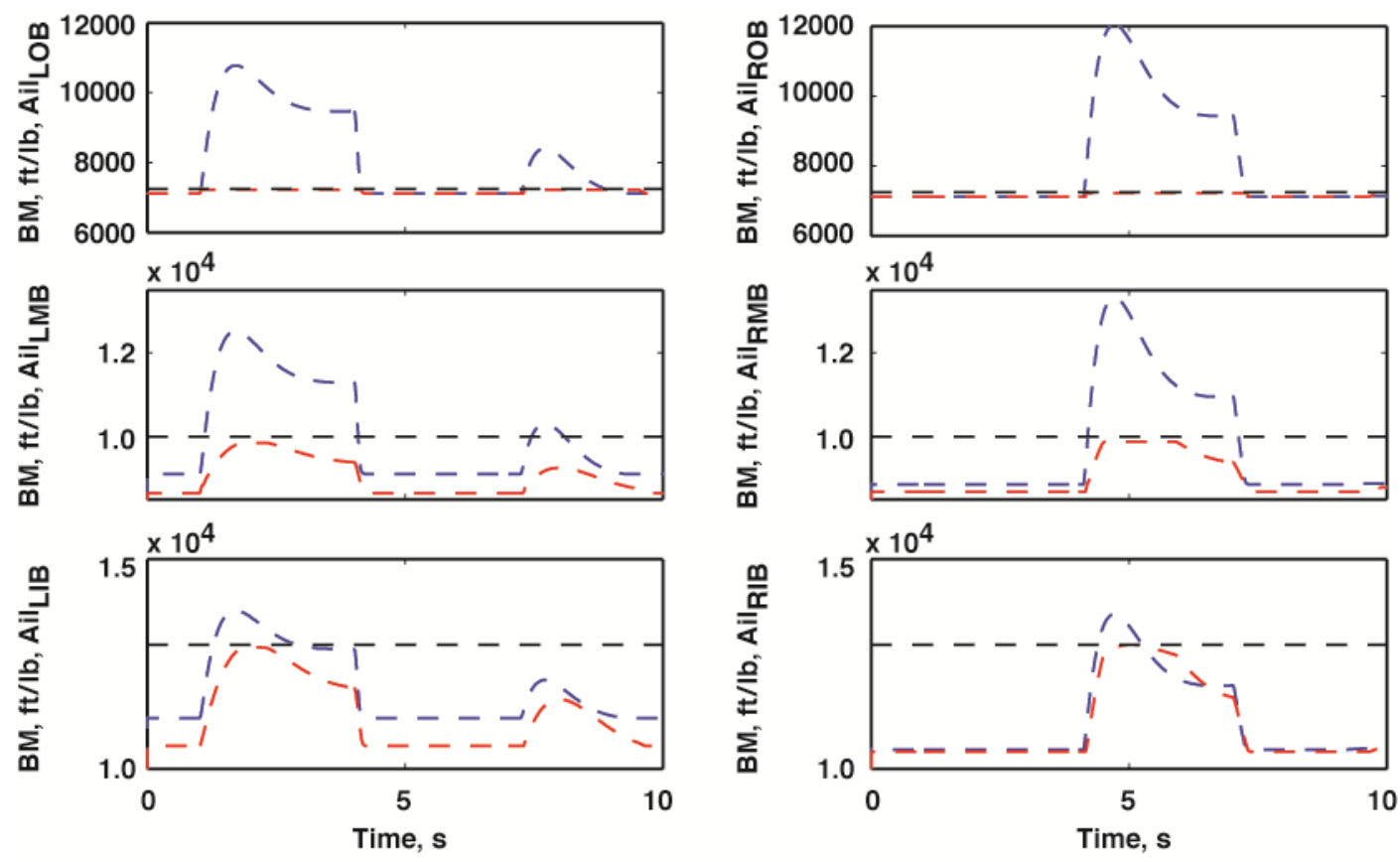

Figure 11. Bending moments (ft-lb) at six left- and right-wing critical points with and without load limit of (7250, 10000, and $12950 \mathrm{ft}-\mathrm{lb})$ for test case three, which has a 35-percent control effectiveness reduction change. Red lines are with load limits, blue lines are without; black lines represents the limit at each point. 

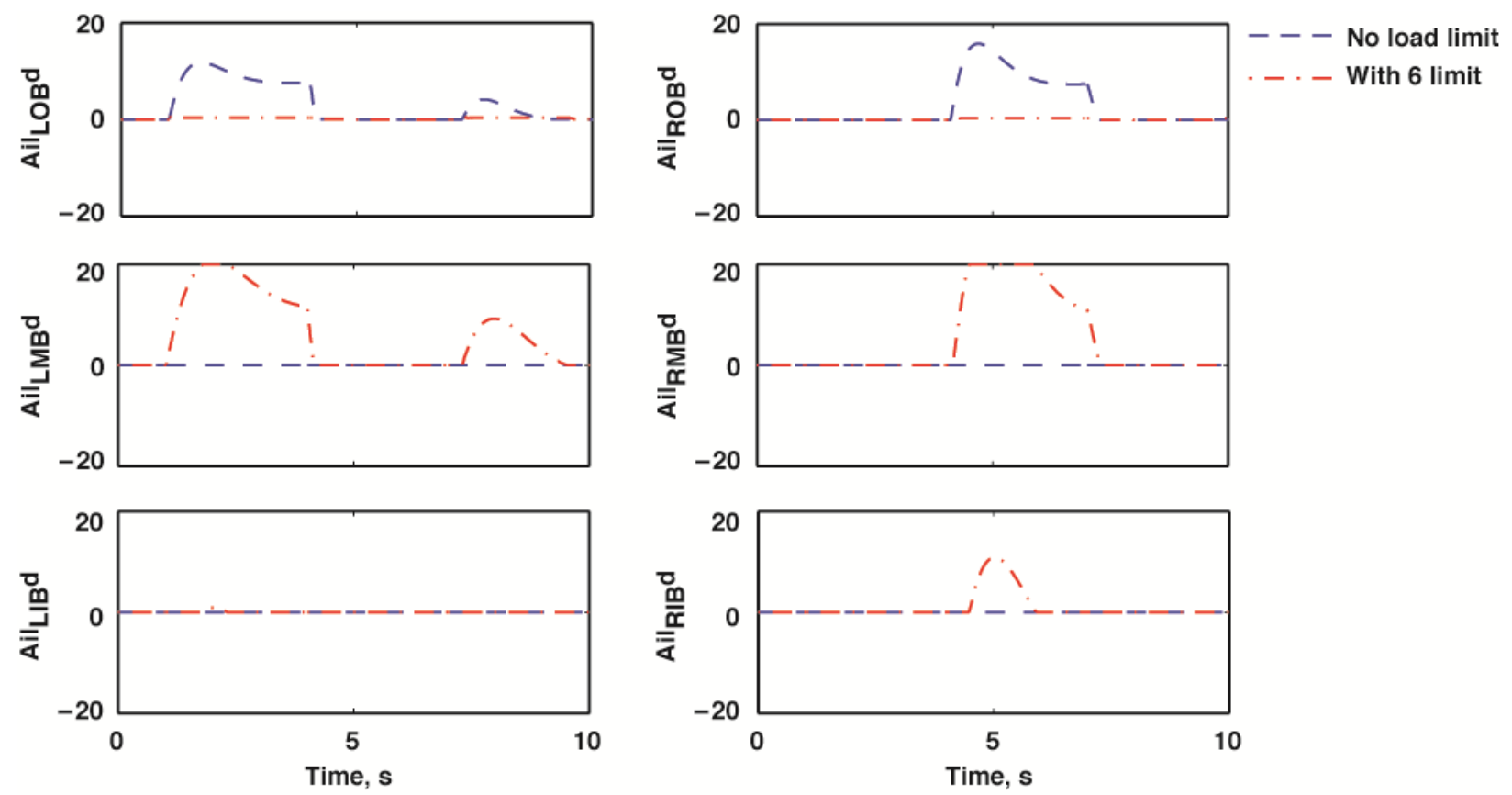

Figure 12. Aileron deflections (deg) on left and right wings with and without load limits for test case three in which there were six load constraints and which has a 35-percent control effectiveness reduction change. Blue line is without load limits; red line is with six limits. The aileron surface limits were +/- $20 \mathrm{deg}$.

\section{Conclusions and Future Work}

The goal of this paper was to show that the aircraft structural loads using feedback could keep the loads below a specified limit, which would enable the designers to build lighter wings and the resultant aircraft to burn less fuel in flight. The means to accomplish this task was to use linear quadratic tracking combined with online allocation techniques to maintain the loads below a limit. To this end, a framework was proposed and demonstrated in simulation using load constraints and real-time load feedback in conjunction with optimal control allocation. The first test case was a simple roll maneuver with and without load constraints applied over six left- and right-wing locations. Test case two showed the results of a larger roll command being used to stress the system using the same load constraints. Test case three demonstrated the robustness of the linear-quadratic-augmented allocator system to uncertainties; a 35-percent change in the plant model was shown, keeping the controller the same as in test cases one and two. The results showed that for this simple system no load limits were broken for the three test cases.

Optimal control allocation was demonstrated to command surface deflections to achieve desired moments while remaining within the defined structural load limits of the aircraft. The runtime of the simulation was reasonable, but has not been studied for scaling of the problem in actual hardware. This study revealed many interesting problems for future investigation. The inclusion of load constraints in algorithms using the $l_{2}$ or $l_{\infty}$ norm would be interesting to compare with the $l_{1}$ norm algorithm used in this paper. The use of weights on the surfaces and critical load points in the control allocation cost function should also be investigated. As well, robustness of the load model and the incremental loads matrix need to be examined in much more detail with the inclusion of the bending and torsion moments.

\section{Acknowledgments}

Special thanks and recognition are given to Diana Acosta of the NASA Ames Research Center (Moffett Field, California) and Marc Bodson of the University of Utah for their technical assistance. Special thanks also to Ola Härkegård for his excellent papers and thesis.

\section{References}

1“Fundamental Aeronautics Program Subsonic Fixed Wing Project Reference Document," National Aeronautics and Space Administration, May 2006, URL: http://www.aeronautics.nasa.gov/programs fap.htm [cited June 27, 2011]. 
${ }^{2}$ Cameron, D., and Princen, N., "Control Allocation Challenges and Requirements for the Blended Wing Body," AIAA-2000-4539, 2000.

${ }^{3}$ Härkegård, O., "Resolving actuator redundancy-optimal control vs. control allocation," Automatica 41 (2005), pp. 137-144.

${ }^{4}$ Oppenheimer, M. W., and Doman, D. B., "A Method for Including Control Effector Interactions in the Control Allocation Problem,” report AFRL-VA-WP-TP-2007-309, Air Force Research Laboratory, 2007.

${ }^{5}$ Bodson, M., "Evaluation of Optimization Methods for Control Allocation," AIAA Journal of Guidance, Control, and Dynamics, Vol. 25, No. 4, 2002, pp. 703-711.

${ }^{6}$ Buffington, J., "Tailless Aircraft Control Allocation," Proc. of the AIAA Guidance, Navigation, and Control Conference, 1997, pp. 737-747.

${ }^{7}$ Durham, W. "Constrained Control Allocation," Journal of Guidance, Control, and Dynamics, Vol. 16, No. 4, 1993, pp. 717-725.

${ }^{8}$ Buffington, J. "Modular Control Law Design for the Innovative Control Effectors (ICE) Tailless Fighter Aircraft Configuration 101-3," Report AFRL-VA-WP-TR-1999-3057, Air Force Research Laboratory, 1999.

${ }^{9}$ Burken, J., Lu, P., Wu, Z., and Bahm, C., "Two Reconfigurable Flight-Control Design Methods: Robust Servomechanism and Control Allocation," Journal of Guidance, Control, and Dynamics, Vol. 24, No. 3, 2001, pp. 482-493.

${ }^{10}$ Enns, D., "Control Allocation Approaches," AIAA-1998-4109, 1998.

${ }^{11}$ Gaulocher, S. L., Roos, C., and Cumer, C., "Aircraft Load Alleviation during Maneuvers Using Optimal Control Surface Combinations," Journal of Guidance, Control, and Dynamics, Vol. 30, No. 2, 2007, pp. 591-600.

${ }^{12}$ Jordan, T. L., Foster, J. V., Bailey, R. M., and Belcastro, C. M., "AirSTAR: A UAV Platform for Flight Dynamics and Control System Testing," AIAA-2006-3307, 2006.

${ }^{13}$ Härkegård, O., "Backstepping and Control Allocation with Applications to Flight Control," PhD thesis: Department of Electrical Engineering, Linkoping University, SE-581 83 Linkoping, Sweden, 2003, ISBN 91-7373-647-3, ISSN 0345-7524, pp. 117-138.

${ }^{14}$ Härkegård, O., "Efficient Active Set Algorithms for Solving Constrained Least Squares Problems in Aircraft Control Allocation," 41 st IEEE Conference on Decision and Control, Vol. 2, pp. 1295-1300.

${ }^{15}$ Frost, S. A., and Bodson, M., "Resource Balancing Control Allocation," American Control Conference, Baltimore, Maryland, 2010.

${ }^{16}$ Frost, S. A., Bodson, M., and Acosta, D. M., "Sensitivity Analysis of Linear Programming and Quadratic Programming Algorithms for Control Allocation,” AIAA-2009-1936, 2009.

${ }^{17}$ Bodson, M., and Frost, S., "Load Balancing in Control Allocation," Journal of Guidance, Control, and Dynamics, Vol. 34, No. 2, 2011, pp. 380-387.

${ }^{18}$ Frost, S. A., Taylor, B. R., Jutte, C. V., Burken, J. J., Trinh, K. V., and Bodson, M., “A Framework for Optimal Control Allocation with Structural Load Constraints," AIAA-2010-8112, 2010. 